\title{
Dependence of the high-latitude plasma irregularities on the auroral activity indices: a case study of 17 March 2015 geomagnetic storm
}

\author{
lurii Cherniak ${ }^{1,2^{*}}$ and Irina Zakharenkova ${ }^{3}$
}

\begin{abstract}
The magnetosphere substorm plays a crucial role in the solar wind energy dissipation into the ionosphere. We report on the intensity of the high-latitude ionospheric irregularities during one of the largest storms of the current solar cycle - the St. Patrick's Day storm of 17 March 2015. The database of more than 2500 ground-based Global Positioning System (GPS) receivers was used to estimate the irregularities occurrence and dynamics over the auroral region of the Northern Hemisphere. We analyze the dependence of the GPS-detected ionospheric irregularities on the auroral activity. The development and intensity of the high-latitude irregularities during this geomagnetic storm reveal a high correlation with the auroral hemispheric power and auroral electrojet indices (0.84 and 0.79 , respectively). Besides the ionospheric irregularities caused by particle precipitation inside the polar cap region, evidences of other irregularities related to the storm enhanced density (SED), formed at mid-latitudes and its further transportation in the form of tongue of ionization (TOI) towards and across the polar cap, are presented. We highlight the importance accounting contribution of ionospheric irregularities not directly related with particle precipitation in overall irregularities distribution and intensity.
\end{abstract}

Keywords: Ionosphere irregularities; Geomagnetic storm; Auroral hemispheric power index; Auroral precipitation; GPS; ROTI

\section{Findings}

Introduction

The ionospheric dynamics in the high-latitude region is driven by a coupling between the solar wind, the magnetosphere, and the ionosphere. One of the most remarkable phenomena of a geomagnetic storm is a substorm, during which excess energy accumulated in the magnetosphereionosphere system is explosively released (Akasofu 1964, 1966). At the ionospheric level, the onset of a substorm is manifested by brightening and breakup of an equatorward moving quiet auroral arc and subsequent explosive expansion of the auroral bulge accompanied by magnetic disturbances (Newell et al. 2001; Streltsov et al. 2010). Signatures of substorm expansion include precipitation of the highenergy particles into the ionosphere that is associated with

\footnotetext{
* Correspondence: tcherniak@ukr.net

'Space Radio-Diagnostic Research Center, University of Warmia and Mazury, 2 Oczapowskiego, Olsztyn 10-719, Poland

${ }^{2}$ Space Weather Laboratory, Kharkiv, Ukraine

Full list of author information is available at the end of the article
}

injection of the high-energy particles in the magnetosphere (Arnoldy and Chan, 1969; Mcllwain, 1974). The most intense ionospheric irregularities in the high-latitude ionosphere are caused by plasma processes associated with auroral activities, attributed to auroral particle precipitation, and dynamical processes including high-speed plasma convection (e.g., Phelps and Sagalyn 1976; Fejer and Kelley 1980; Keskinen and Ossakow 1983).

Occurrence of the ionospheric irregularities is difficult to forecast and to model, because of the temporal and spatial variability of the ionosphere and solar activity. The linkage of the high-latitude ionospheric irregularities, which produce the radio signal scintillation, to the GPS measurements is of special importance for several research activities. One of these concerns the study of the physical processes in the polar region, needed to understand the fundamental aspects of the coupling between the solar wind and the Earth's magnetosphere and ionosphere. The other focuses on the space-related technical applications, as the presence of the ionospheric irregularities can impact

\section{勿 Springer}


variety of trans-ionospheric radio communication and even distort the performance of the global navigation systems (e.g., Smith et al. 2008). So, study of morphology and spatio-temporal dynamics of the ionospheric irregularities, their dependences on geophysical factors for proper specification by an empirical model is actual for both fundamental and applied tasks. This study focused on the testing of potential drivers for the GPS-based empirical modeling of the ionospheric irregularities' occurrence and intensity in the polar and auroral latitudes.

Nowadays, the GPS technique provides a relatively high-resolution method for tracking the signatures of the ionospheric plasma irregularities (e.g., Pi et al. 1997; Aarons and Lin 1999; Valladares et al. 2004; Jakowski et al. 2012; Cherniak et al. 2014a). In the high-latitude ionosphere the phase fluctuations of the GPS signals are primarily caused by the steep ionospheric density gradients and irregularities associated with auroral and cusp precipitation and polar cap patches (Skone and Cannon 1995; Mitchell et al. 2004; Watson et al. 2011; Noja et al., 2013; Prikryl et al. 2013, 2014; Jiao et al. 2013).

In this paper, the intensity of the high-latitude ionospheric irregularities was studied for one of the largest storm of the 24th solar cycle. We examine the St. Patrick's Day geomagnetic storm on 17 Match 2015. More than 2500 permanent GPS stations, located in the Northern Hemisphere, were processed and analyzed in order to estimate the storm time dynamics of ionospheric irregularities in the polar and auroral regions. We analyze the dependence of the GPS-detected ionospheric irregularities on the auroral activity indices, such as the auroral hemispheric power $(\mathrm{HP})$, the auroral electrojet (AE), and the planetary geomagnetic Kp indices.

\section{Data and methods}

In this paper, we focus on the region of the Northern Hemisphere, which covered the $30-90^{\circ}$ geographic latitude range. We use the raw GPS measurements provided by the dense ground-based networks of GPS receivers: IGS and UNAVCO networks as well as the European Permanent Network (EUREF) and the Canada permanent GNSS regional networks. As a result, our database consists of more than 2500 GPS stations. All raw RINEX data were converted to the 30-s resolution, as different sampling rate can greatly affect the results (e.g., Jacobsen 2014).

To obtain the characteristics of the ionospheric irregularities dynamics, we processed the multi-site GPS database and calculated two GPS-based indices. We use the time-derivative of TEC (ROT, rate of TEC change) as a measure of phase fluctuation activity and the Rate of TEC Index (ROTI) as a GPS-based index that characterizes the severity of the GPS phase fluctuations and detects the presence of ionospheric irregularities (Pi et al. 1997). In the high-latitude ionosphere, the ionospheric irregularities are generated by different mechanisms and their spatial scale sizes varies from $1000 \mathrm{~km}$ (e.g., polar patches) to scale sizes $\sim 100 \mathrm{~s} \mathrm{~km}$ to $\sim 10 \mathrm{~s} \mathrm{~cm}$ (Keskinen and Ossakow 1983). Taking into account that plasma drift at high latitudes is in the order of $1 \mathrm{~km} / \mathrm{s}$ and standard ROT computation for each 30-s interval, Pi et al. (1997) estimated that this technique can provide measurements of the irregularities with scale sizes in the order of $\sim 30 \mathrm{~km}$ and larger.

For overall representation of the spatial evolution of high-latitude irregularities and their linkage with the Earth's magnetosphere (due to the strong connections between the Earth's magnetic field and the ionosphere), we analyzed the daily ROTI polar maps. The ROTI mapping technique was also described in Cherniak et al. (2014a, b). Here, ROTI behavior is represented as a function of a magnetic local time (MLT) and corrected magnetic latitude (MLAT) for a specific day. We use the corrected geomagnetic (CGM) coordinates with the Definite/International Geomagnetic Reference Field (DGRF/IGRF) models. This polar map represents a daily map with $00-24$ MLT time frame. The grid size is 8 min MLT by $2^{\circ}$ MLAT, with the latter covering 50 $90^{\circ}$. ROTI data were binned and averaged in each MLAT-MLT bin, i.e., the map resolution is 20 bins along MLAT axis and 180 bins along MLT axis. In general, the averaged ROTI value in each bin is corresponded to the probability of the GPS signals phase fluctuations caused by passing of radio signals through the ionospheric irregularities. For daily ROTI maps, we averaged and binned all ROTI values collected during 00-24 UT period of a considered day.

To study the dynamics and intensity of the ionospheric irregularities at the high-latitude ionosphere, we also construct polar ROTI maps with temporal resolution of $15 \mathrm{~min}$.

Further, we calculate the Hemisphere ROTI index (HROTI) on the base of the 15 min ROTI maps. This index represents the average level of the GPS fluctuation activity from the mid-latitudes towards the auroral region. It can be determined as a sum of the ROTI values for all non-zero bins. Here we used the normalized Hemisphere ROTI index by the total bin number.

\section{The St. Patrick's day geomagnetic storm}

The severe geomagnetic storm occurred on 17 March 2015 and caused the dramatic response in the ionosphere-plasmasphere-magnetosphere system. Figure 1 shows the variations of interplanetary and geomagnetic parameters during 15-20 March 2015.

The sudden storm commencement (SSC) was registered at $\sim 0445$ UT and then there was a quick drop of the SYM-H index to the value of $-226 \mathrm{nT}$, observed at 2300 UT, with a couple of local minima of -93 and 


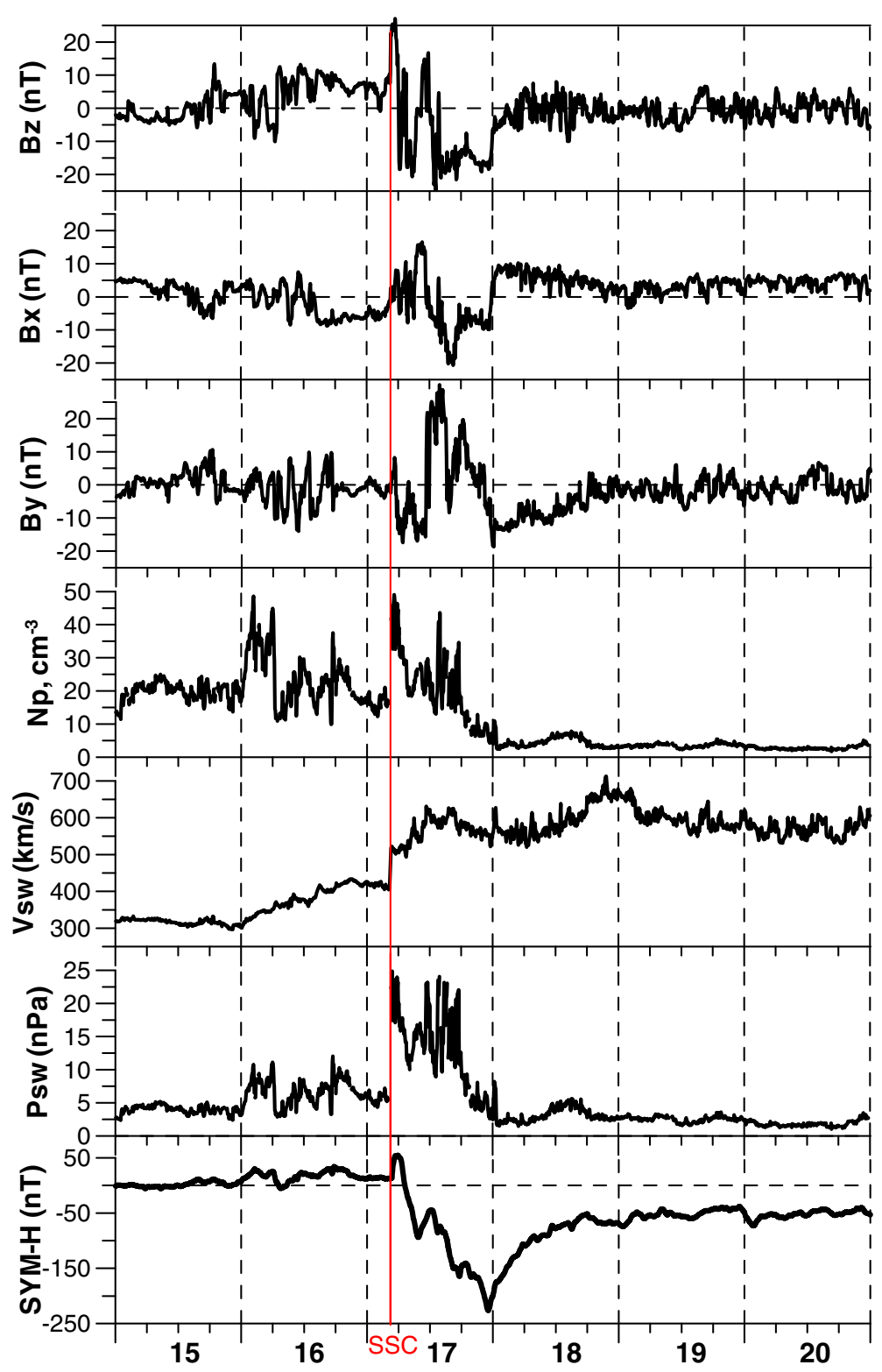

Fig. 1 Variations of the interplanetary and geomagnetic parameters during 15-20 March 2015 storm: the IMF Bz, Bx, and By components (Geocentric Solar Magnetospheric (GSM)), density, velocity, and dynamic pressure of the solar wind, and Sym-H index. Red line indicates the SSC time

$-164 \mathrm{nT}$ at $\sim 0940$ and $\sim 1740 \mathrm{UT}$ respectively (Fig. 1). The planetary index of the geomagnetic activity $\mathrm{Kp}$ reached the maximum value of 8 after $\sim 12$ UT on 17 March 2015, qualifying it as a severe geomagnetic storm.

During the main phase of the storm (17 March), the interplanetary magnetic field (IMF) orientation displayed a highly complex behavior. Three IMF components (top panels of Fig. 1) switched several times from positive to negative values and vice versa. Right after the shock arrival, the northward IMF $\mathrm{Bz}$ component reached the value of about $25 \mathrm{nT}$. At $\sim 0530 \mathrm{UT}$ the IMF Bz turned southward and reached the first minimal value of
$-18 \mathrm{nT}$ at $0615 \mathrm{UT}$. Then the IMF Bz sharply turned northward and varied significantly between north and south during $\sim 8 \mathrm{~h}$. After $\sim 1340 \mathrm{UT}$ the Bz turned southward again and remained south till the end of this day. From $\sim 06$ till $11 \mathrm{UT}$, there are observed dominating positive $\mathrm{Bx}$ and negative By with peak values of 16.5 and -16.8 nT for Bx and By, respectively. During 11-15 UT with the new southward turning of $\mathrm{Bz}$, the opposite situation with $\mathrm{Bx} / \mathrm{By}$ domination occurred-Bx became negative with the minimal values of $-14 \mathrm{nT}$ while By component became positive with the peak of $30 \mathrm{nT}$. After 15 UT, IMF By turned sharply to negative values, 
reaching $-8 \mathrm{nT}$, and then again to the positive ones with the new peak of $20 \mathrm{nT}$ around $18 \mathrm{UT}$.

Kamide and Kusano (2015) reported that this severe geomagnetic storm (G4 level) was a result from the superposition of two successive, moderate storms, driven by two successive, southward IMF structures. The intense geomagnetic storm on 17-18 March 2015 leads to the auroral particle precipitation and an enhancement of the substorm activity. During this storm, aurora was observed as far south as $55-60^{\circ}$ MLAT in the USA, Europe, and Japan (e.g., Nishitani et al. 2015; Kamide and Kusano 2015; GUVI TIMED JHU/APL website 2015). This storm results in significant consequences on satellite operations, radio waves propagation, and GNSSrelated services and applications. As reported by the WAAS Test Team (Wanner 2015) during the 17 March 2015 storm, the degradation of positioning performance was registered.

\section{Results and discussion}

In this study, we analyzed the NOAA Hemispheric Power (HP) index, that representing the estimated power in gigawatts $(\mathrm{GW})$ deposited in the polar regions by energetic particles. The HP index is usually used as a measure of auroral particle precipitation activity (Fuller-Rowell and Evans 1987; Emery et al. 2008; Newell et al. 2009). We compare GPS-based ROTI data with changes of the HP index for the Northern Hemisphere. We use the results of the Oval Variation, Assessment, Tracking, Intensity and Online Nowcasting (OVATION) Prime Real-Time model. OVATION Prime is an auroral precipitation model parameterized by solar wind driving (Newell et al. 2009, 2014). The model is based on the precipitating particle observations collected by the Defense Meteorological Satellite Program (DMSP) spacecraft. Distinguishing features of the model include an optimized solar wind-magnetosphere coupling function which predicts auroral power significantly better than Kp or other traditional parameters, the separation of aurora into categories (diffuse aurora, monoenergetic, broadband, and ion), the inclusion of seasonal variations, and separate parameter fits for each bin of $0.5^{\circ}$ magnetic latitude (MLAT) $\times 0.25$ magnetic local time (MLT) (Newell et al. 2014). Ovation Prime has been in operational use since 2011 at the NOAA Space Weather Prediction Center (SWPC) and at NASA Goddard Space Flight Center.

Figures 2 and 3 illustrate several examples of the retrieved ROTI maps together with the HP results derived by the OVATION Prime Real-Time model for the quiet day of 16 March and the disturbed day of 17 March 2015. These examples correspond to times of 0915, 1615, 1730, and 2230 UT, which are close to the HP index peaks (see Fig. 5b). We present the ROTI maps by two kind of visualization: 1) maps in geographical coordinates with latitude range of $30-90^{\circ} \mathrm{N}$ (left column of Figs. 2 and $3 a-d), 2)$ maps in geomagnetic coordinates with latitude range of $50-90^{\circ}$ MLAT (middle column). The OVATION-derived maps (right column) are in geomagnetic coordinates with latitude range of $50-90^{\circ}$ MLAT and 00-24 MLT. The OVATION maps illustrate the total HP value for the Northern Hemisphere and one can see the significant intensification of the total aurora with the HP index of $110 \mathrm{GW}$ on 17 March comparing with the previous day of 16 March when the HP index reached only $10 \mathrm{GW}$.

During the quiet day of 16 March, the irregularities intensity in the ROTI maps was rather weak and was not registered below $65-70^{\circ} \mathrm{N}$ MLAT. The Ovation Prime output at the quiet time (with the average auroral HP about $10 \mathrm{GW}$ ) also shows weak aurora intensity with the narrow precipitation zone near $65^{\circ}$ MLAT. During the main phase of this storm, the zone of the intense ionospheric irregularities occurrence moved equatorward (Fig. 3). The ROTI map for 2230 UT (Fig. 3d) shows the equatorial border of this irregularities zone reached $45^{\circ}$ $\mathrm{N}\left(\sim 55^{\circ} \mathrm{MLAT}\right)$ in North America. The OVATIONderived results demonstrate a significant increase of the auroral precipitation intensity and the equatorial border of the auroral oval reached $55^{\circ}$ MLAT.

Additionally, we present the superimposed on the ROTI geographical maps the orbital tracks of the Swarm satellites, when one of the satellites passed the region close to the GPS ROTI observation time. The recent ESA's mission Swarm consists of the three identical satellites-A, B, and C. The Swarm satellites provide in situ observations of the ionospheric plasma density at $\sim 480-530 \mathrm{~km}$. Each graph demonstrates the orbital track (thin line) and leveled plasma density $\mathrm{Ne}$ values (thick line) along the satellites' orbit. During disturbance day of 17 March, the intense ionospheric irregularities at altitude of about $500 \mathrm{~km}$ in comparison with the quietday ones were observed. These irregularities were registered inside the polar cap region. The Swarm in situ measurements are in a rather good agreement with ground-based GPS observations and also show the occurrence of the ionospheric irregularities even over regions with lack of GPS data.

The bottom panel (Figs. 2e and 3e) shows the daily ROTI map for 16 March and 17 March 2015. These maps represent the ionospheric irregularities occurrence as a function of the corrected MLAT $\left(50-90^{\circ}\right)$ and MLT (00-24 MLT), we use the same grid with 8 min MLT by $2^{\circ}$ MLAT bins. ROTI map for the Northern Hemisphere (Fig. 3e) shows the complex pattern of the ionospheric irregularities occurrence during the main phase of the storm on 17 March. The most intense ionospheric irregularities were found within $60-70^{\circ}$ MLAT during 20-09 MLT and one noontime peak at 11-13 MLT. 

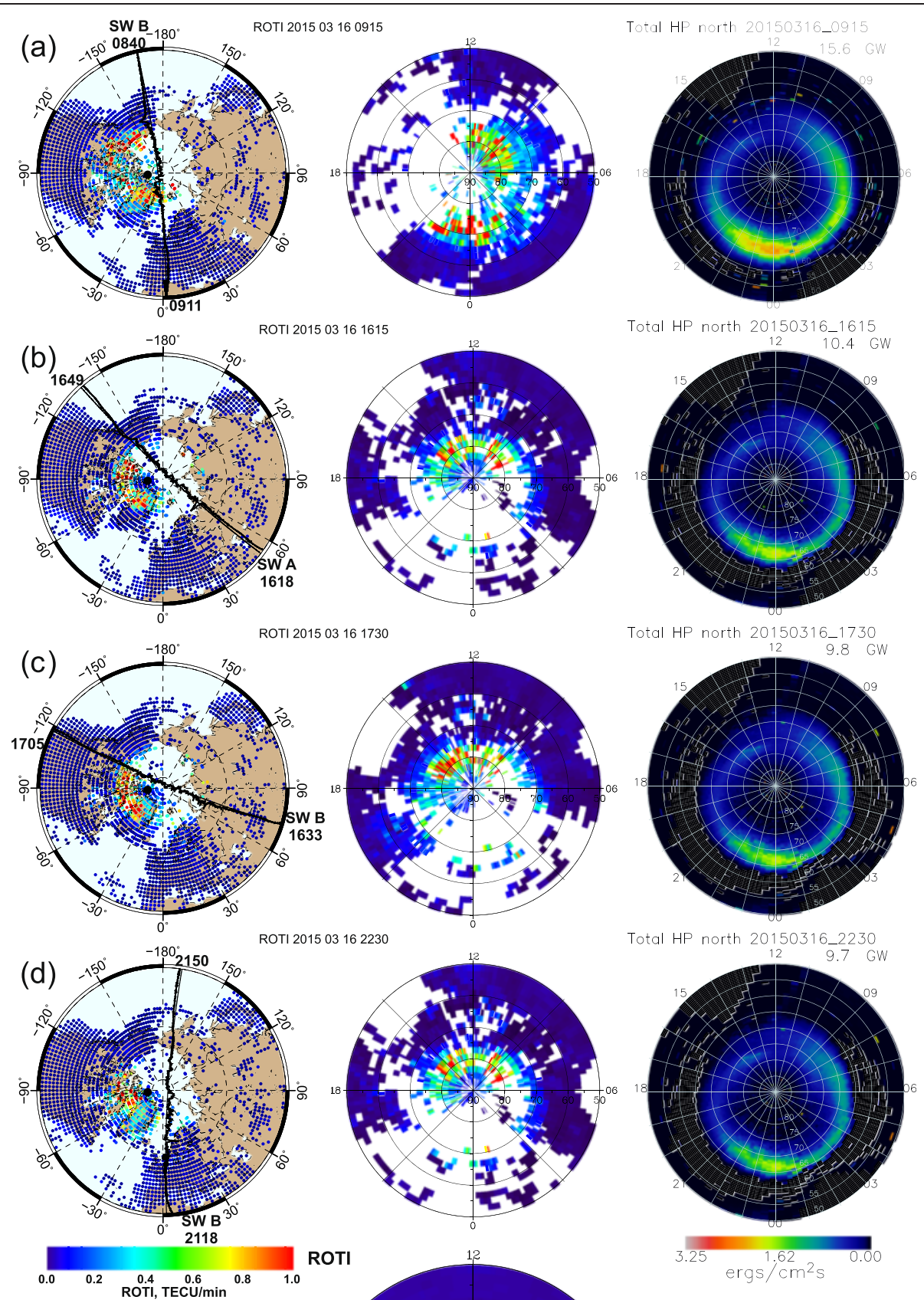

(e) $\underset{20150316}{\text { Daily ROT map }}$

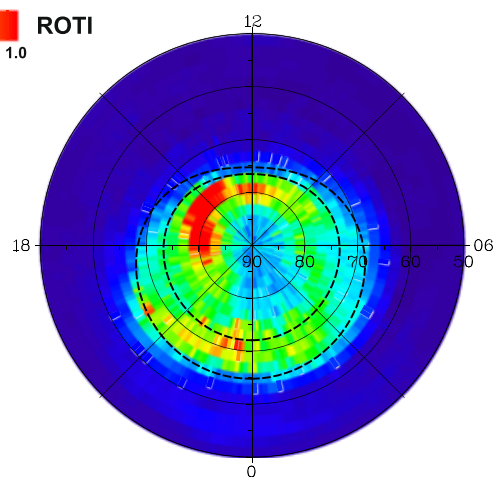

Fig. 2 (See legend on next page.) 
(See figure on previous page.)

Fig. 2 Comparison of the ROTI maps with the OVATION model results for selected UT moments of 16 March 2015 (the quiet day). Each panel (a-d) presents the example of 15 min ROTI maps in geographic coordinates $\left(30-90^{\circ} \mathrm{N}\right)$, the same ROTI map in CGM (50-90 MLAT) and the OVATION map for this UT moment in geomagnetic coordinates (50-90 MLAT) with the noon at the top. The Swarm satellites (A or B) orbital tracks and leveled plasma density Ne values (thick line) are superimposed on the geographical ROTI maps; time (UT) and satellite name are indicated close to the track line. Black dot indicate the position of the magnetic pole in CGM. Bottom panel (e) shows the daily ROTI map for 16 March. The Feldstein model results of the auroral oval (dashed line) are superimposed on the map

Distinctly separated maximum of the irregularities intensity can be found within $50-60^{\circ}$ MLAT at $\sim 15-17$ MLT, that correspond to the irregularities intensification in North America shown in Fig. 3d.

Further, we make model calculation of the auroral oval equatorward and poleward boundaries. For this purpose, we use the auroral oval representation of the Feldstein ovals by Holzworth and Meng (Feldstein 1963; Holzworth and Meng 1975). The model is driven by IQ index of magnetic activity (0-6) and provides the equatorward and poleward boundaries in corrected geomagnetic latitude (CGL) of the oval for given magnetic local time (MLT). Superimposed black dashed lines at Figs. 2d and $3 \mathrm{~d}$ reproduce the Feldstein model auroral ovals for $\mathrm{IQ}=3$ and $\mathrm{IQ}=6$ (highly disturbed), correspondingly. For 16 March, all GPS-detected ionospheric irregularities are located at high latitudes within the equatorward boundary of the auroral oval, derived from the model simulations. For the case of $17 \mathrm{March}$, the observed picture is much more complicated. The significant part of the observed irregularities found to be outside the equatorward boundary of the modeled auroral oval. Relatively good agreement between the auroral model boundaries and intense GPS irregularities location is found in night-time sector of 21-03 MLT.

The features of the irregularities pattern in the daily and 15-min ROTI maps (but not reproduced by OVATON model) can be explained by the occurrence of the strong storm-induced ionospheric gradients and irregularities. In the middle and high-latitude ionosphere, there are several sources of large-scale plasma gradients such as dynamics and evolution of the midlatitude ionospheric trough, formation of storm enhanced density (SED), and further evolution of the SED plume to the polar tongue of ionization (TOI). SED has been described as a spatially narrow, distinct, region of enhanced plasma density (plume) observed in the post-noon and pre-midnight sectors extending from the equatorward edge of the main ionospheric trough to the noontime cusp (Foster 1993; Coster et al. 2007). The dayside source of the TOI is the SED plume transported from lower latitudes in the post-noon sector by enhanced storm-time electric fields of the sub-auroral polarization streams (SAPS) (Foster and Burke 2002). The SED latitude decreases with increasing local time and disturbance level (Foster et al. 2005). Anti-sunward convection carries this material through the dayside cusp and across the polar cap to the nightside where the auroral $\mathrm{F}$ region is significantly enhanced by the SED material (Foster et al. 2005). During the SED/TOI convection across the polar cap, the TOI structure may be fragmented into discrete polar cap patches. A polar cap patch typically has a density that is 2-20 times larger than the surrounding background electron density and its horizontal size ranges from 100 to $1000 \mathrm{~km}$ (e.g., Tsunoda 1988, Crowley et al. 2000). The convecting patches develop intermediate-scale irregularities by action of the gradient-drift instability mechanism (Kersley et al. 1995), that is also confirmed by numerical simulation (Gondarenko and Guzdar 2004). Because of the steep plasma density gradients and irregularities at their edges (Weber et al. 1986), the TOI structure and polar cap patches can be detected with GPS measurements (e.g., Aarons 1997; Noja et al. 2013; van der Meeren et al. 2014).

The ROTI maps in Fig. 3a correspond to the first peak of the auroral activity registered near $09-10$ UT of 17 March 2015. The significant intensification of the ionospheric irregularities is observed in the night-time sector. The irregularities in the polar cap including cusp region were not so intense as those in the auroral zone. The ROTI maps at Fig. 3b, c demonstrate the occurrence of the ionospheric irregularities inside the polar cap region. These irregularities can be caused by the TOI/patch structure dynamics from the dayside and consequent formation of the large-scale polar patches. The daily ROTI map (Fig. 3e) also shows the ionospheric irregularities' occurrence not only as an oval-shape region but also in form of the radial structures oriented from the noon sector to near midnight one that can be related to the TOI dynamics through the polar cap region. The occurrence of the strong GPS phase fluctuations within $50-60^{\circ}$ MLAT in North America, seen in the ROTI maps in Fig. 3d, was likely caused by the SED formation and plasma density gradients inside this largescale SED structure. In summary the GPS fluctuation measurements can be used for detection of the highlatitude ionospheric irregularities caused by the direct particle precipitation, as well as the ionospheric irregularities formed through the subsequent plasma and dynamic processes in polar ionosphere during the main phase of the geomagnetic storm.

In addition, we note a strong impact of this ionospheric disturbance on the HF radio propagation. Figure 4 shows 

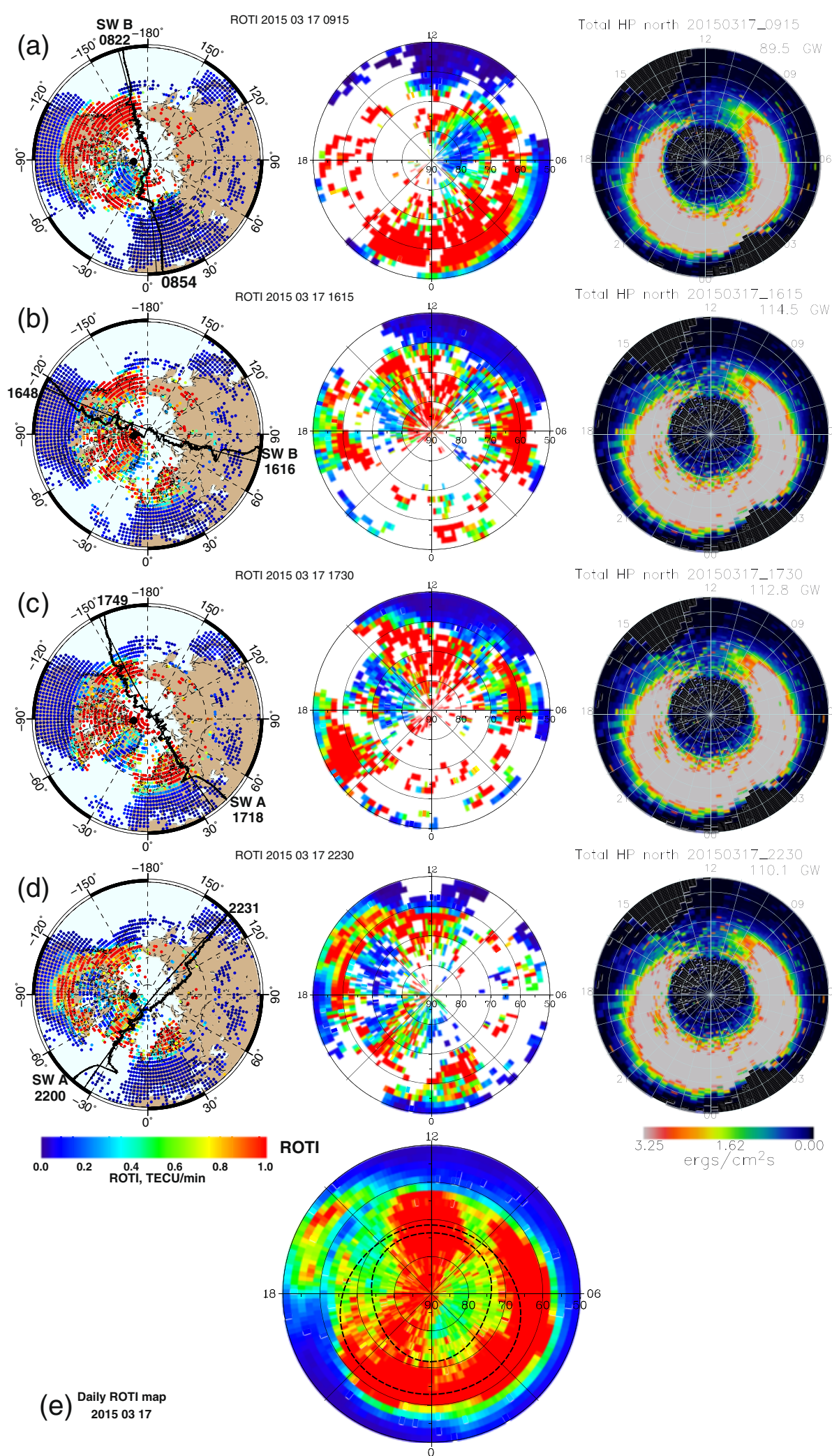

(e) $\underset{20150317}{\text { Daily ROTI map }}$

Fig. 3 a-e The same as Fig. 2 but for the storm day of 17 March 2015 


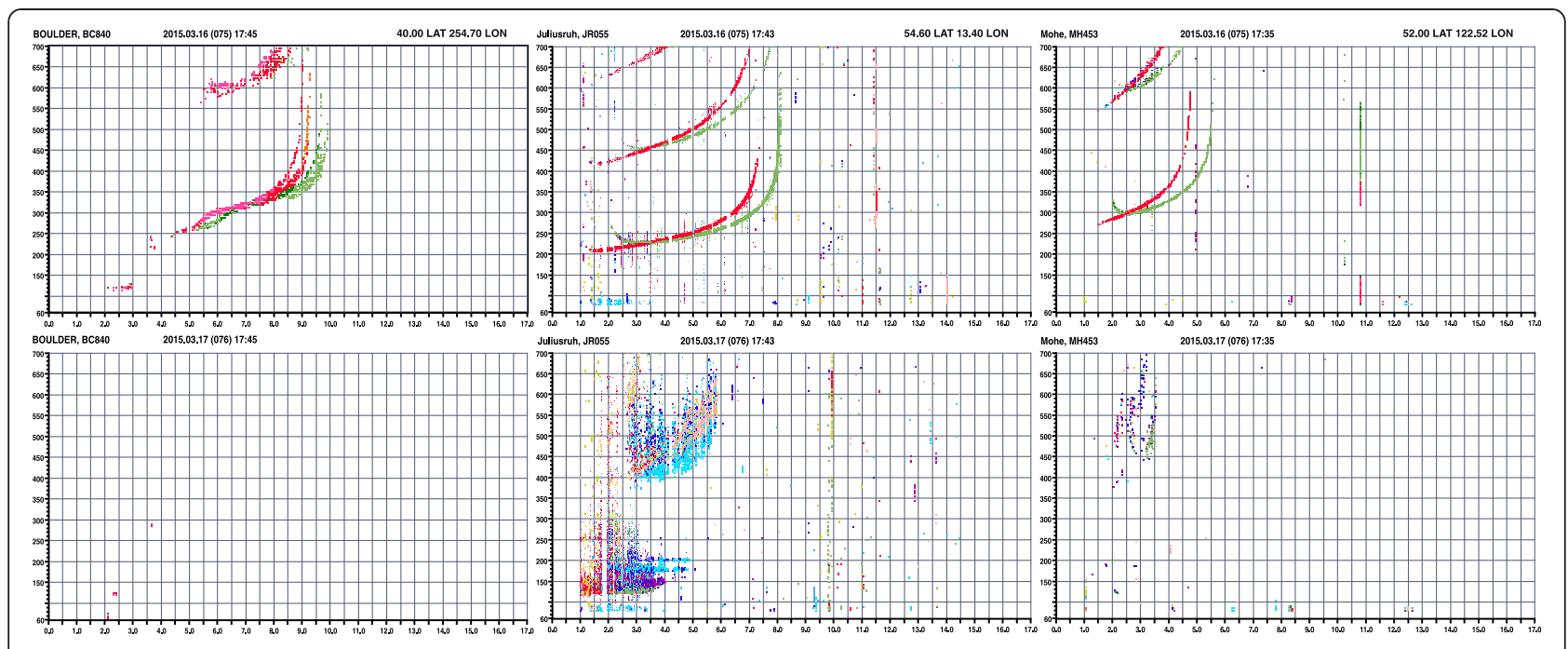

Fig. 4 Examples of the digital ionograms recorded at 1730-1745 UT during 16 March (top) and 17 March (bottom) by Boulder, Juliusruh, and Mohe digisonde stations

the digital ionograms recorded at three vertical sounding stations located at mid-latitudes in North America, Europe, and Asia. All ionograms were obtained from the GIRO DIDbase via the SAO Explorer software (Reinisch and Galkin 2011). We present ionograms for 1730-1745 UT-the same interval that was considered with the ROTI maps in Figs. 2b and $3 \mathrm{~b}$-for the quiet day (top panel) and the disturbed day (bottom panel). For the quiet day, the recorded ionograms demonstrated clear reflecting echoes corresponding to a distinct F2 layer. For the conditions of 17 March, we note a strong spread and total/partial absence of the reflecting echoes in ionograms for all considered stations. At the Millstone Hill station (not shown here), 5-min ionograms with nearly total absence of the reflecting echoes were recorded during extended period from 2235 UT of 17 March till 1020 UT of 18 March. This fade out effect can be caused by the significant decrease of the F2 region electron density (negative ionospheric storm), or by an increase in turbulence of the ionospheric plasma (ionospheric irregularities). So, the vertical sounding technique, accepted as a benchmark for ionospheric research, was not able to provide the necessary information about the ionosphere's state at different midlatitude locations of the Northern Hemisphere during the main and/or recovery phases of this storm. On the other hand, the estimates of the ionospheric irregularities occurrence and intensity derived with the GPS signal measurements are a valuable source of information during this period.

Further, we analyze the changes of the ionospheric irregularities intensity by estimation of the normalized
HROTI based on the 15-min ROTI maps. In order to compare the obtained HROTI values with other geophysical indices, we obtained the 15-min averaged HP and AE indices. The NOAA HP index is released with 5min resolution, the preliminary $\mathrm{AE}$ index is released by the WDC Kyoto with 1-min resolution. The Kp index is released with 3 -h resolution, so we interpolate these data to $15 \mathrm{~min}$. We calculate the HROTI index for the region covered 50-90 MLAT by two ways-with and without taking into account the polar cap region with cusp. As the boundary of polar cap, we select $75^{\circ}$ MLAT, based on the estimates of cusp position made by Newell et al. (1989) and Russell (2000) and the Feldstein model results for the auroral oval poleward boundary.

Figure 5 shows the variability of the HROTI, HP, AE, $\mathrm{Kp}$, and SYM-H indices during 15-20 March 2015. The HROTI index is presented for the region covered 50-90 MLAT (blue bars) and 50-75 MLAT (red bars), that excluded the polar cap region. It is clearly seen that the main contribution to the total HROTI value is provided by the region outside the polar cap zone.

We conclude that during this geomagnetic storm the major part of the ionospheric irregularities were generated outside the polar cap region. Further evolution of the geomagnetic storm leads to the ionospheric plasma response in the form of the positive and negative disturbances, as well as formation of the SED structures at the mid-latitudes of the Northern Hemisphere. The SED/ TOI convection across the polar cap was recognized in the form of the intense ionospheric irregularities over the polar cap region. This effect predominates during the second part of the main phase from 13 UT till 23 UT and it is visible on 15-min and daily ROTI maps. 


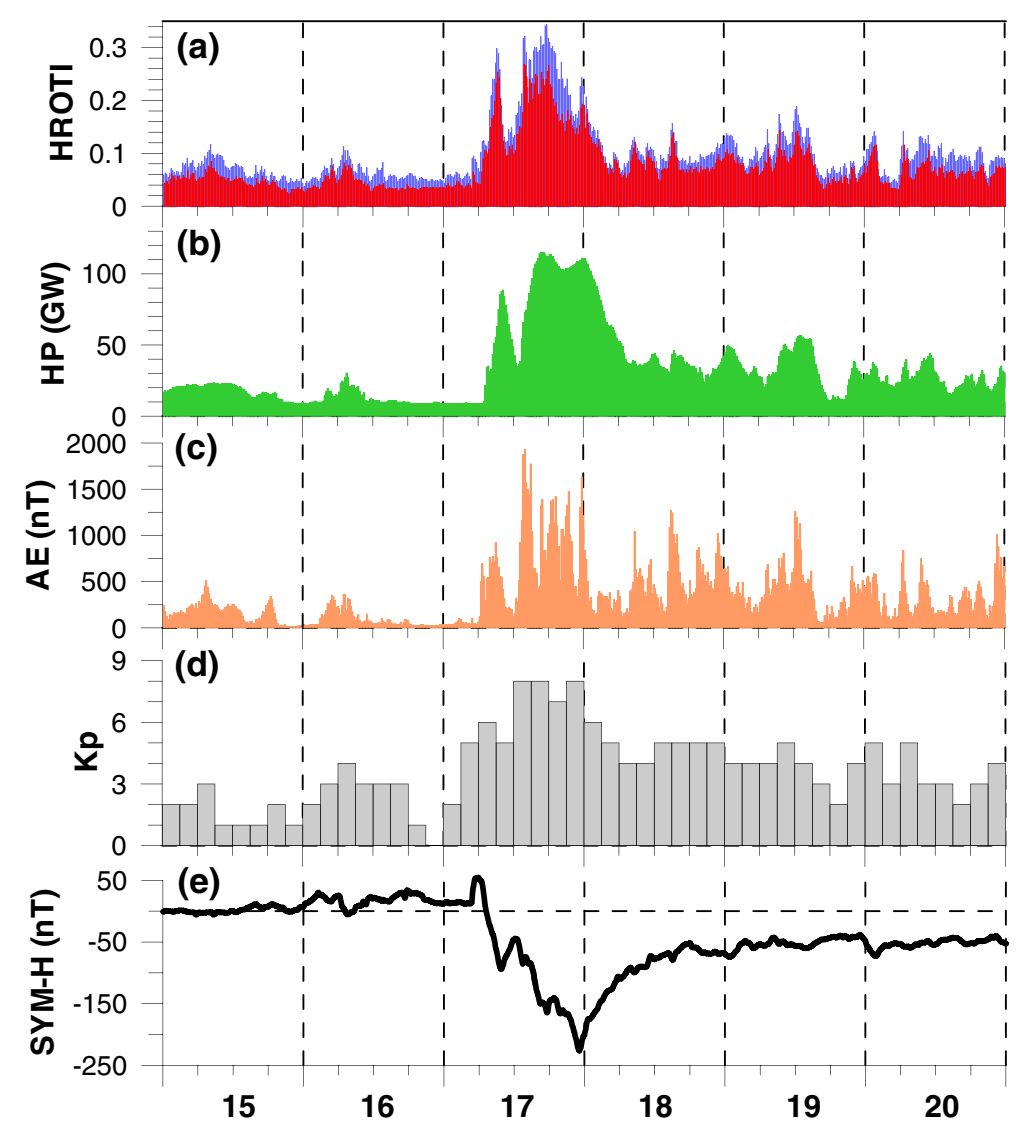

Fig. 5 Variations of the a HROTI for two regions: 50-90 MLAT (blue bars) and 50-75 MLAT (red bars), b HP, c AE, d Kp, and e SYM-H indices during 15-20 March 2015. The HROTI, HP, and AE values are averaged over a 15-min period

It is necessary to note again that the OVATION model of energetic particle precipitation can not represent the latter effects related to the dynamic processes within the ionosphere. Zou et al. (2013) report that direct contribution from precipitating energetic protons to the SED formation is at most $\sim 10 \%$ of the total $\mathrm{F}$ region density. The main mechanisms responsible for the SED structure formation are equatorward expansion of the convection pattern, large upward flows, as well as horizontal advection due to fast flows, energetic particle precipitation, and enhanced thermospheric wind in the topside ionosphere (Zou et al. 2013).

As expected, we found that the HROTI index that indicates the GPS-based irregularities intensity at high latitudes is in a very good agreement with changes of the $\mathrm{HP}, \mathrm{AE}$, and $\mathrm{Kp}$ indices. There is a clear similarity in the HROTI behavior following the peaks in the $\mathrm{HP}$ and $\mathrm{AE}$ variation.

The HP estimates were about 10 GW before 0650 UT. After $\sim 0650$ UT HP starts to rise and quickly reaches $\sim 40 \mathrm{GW}$ at $0730 \mathrm{UT}$ with the first peak of $90 \mathrm{GW}$ at 0940 UT. The following decrease of the HP index reached the minimum value of $35 \mathrm{GW}$ near $1230 \mathrm{UT}$. It was initiated by the northward turning of the IMF Bz. After 13 UT, with new southward turn of $\mathrm{Bz}$, the HP started to rise again and peaked at $116 \mathrm{GW}$ near $16 \mathrm{UT}$, then the HP index remained larger $100 \mathrm{GW}$ during $10 \mathrm{~h}$ until $0130 \mathrm{UT}$ of 18 March. The ionospheric irregularities intensity seen in the HROTI index precisely followed these two main peaks during the main phase of the storm. Visual comparison of the data at Fig. 5a-c for interval 13 UT of 17 March till 06 UT of 18 March shows a better agreement between the HROTI and HP indices behavior.

Further, we estimate the dependence of the HROTI values on the auroral activity indices. Figure 6 presents the scatter plots of the normalized HROTI against the variations of the $\mathrm{HP}, \mathrm{AE}$, and $\mathrm{Kp}$ indices. We consider separately the HROTI values calculated over the latitude region of $50-90^{\circ}$ MLAT (left column of Fig. 6) and $50-75^{\circ}$ MLAT (right column) with the latter excluding the polar cap region. The scatter plots show a linear dependence and the high correlation between the HROTI and all considered indices. We find the highest correlation of 0.84 between the HROTI and HP indices. 


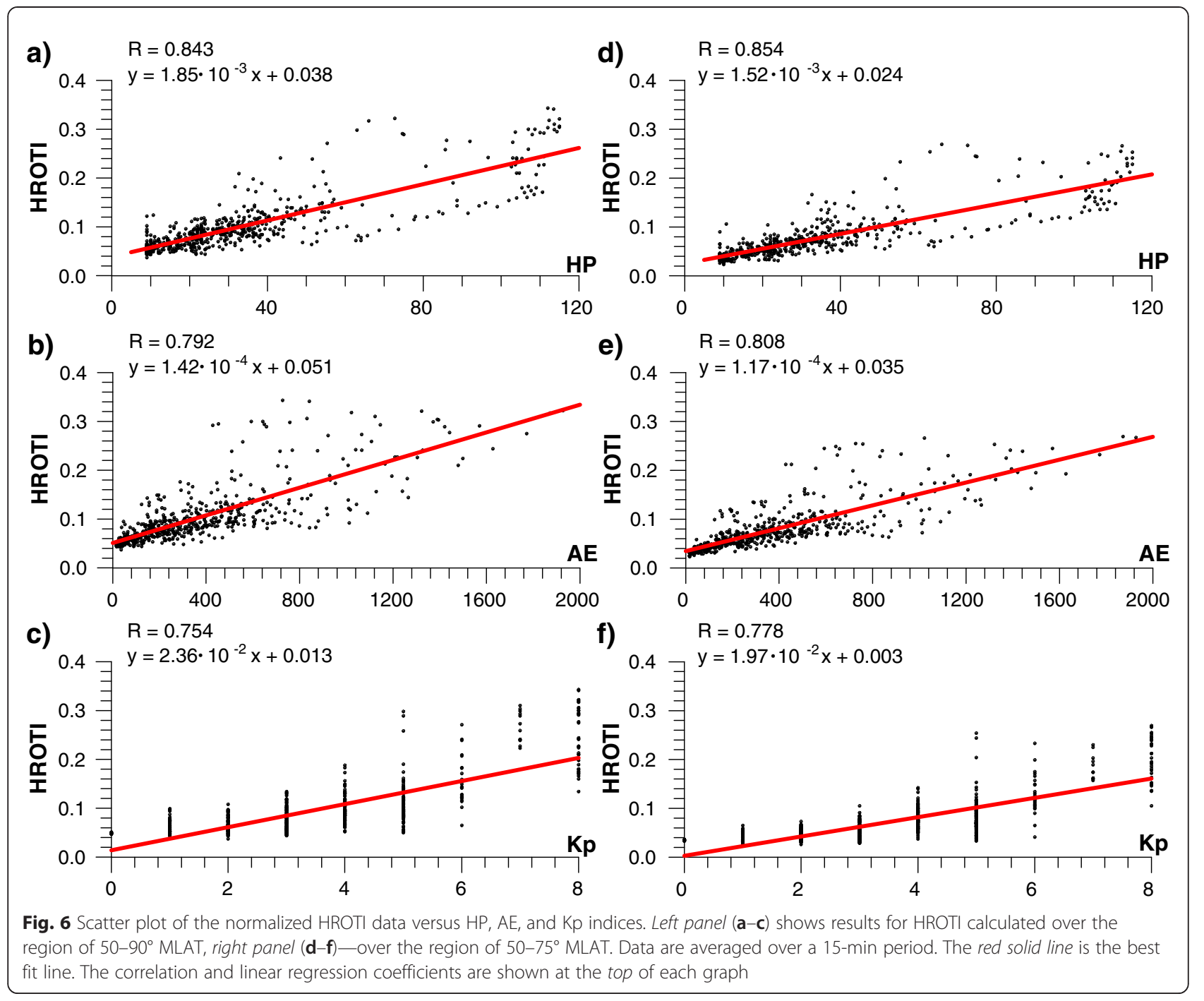

The correlation between the HROTI and AE indices reached the value of 0.79 , but data show a wider scattering and asymmetry around the best fit line (Fig. $6 \mathrm{~b}$ ). We note that the HROTI is also well correlated with the Kp index $(R=0.75)$; however, Fig. 6c clearly demonstrates some limitation of the Kp index to represent the dynamics of ionospheric irregularities. Low sampling rate of the Kp index $(3 \mathrm{~h})$ does not allow to use it concurrently with the rapid HROTI variations. On the other hand, the Kp index or the daily sum of $\mathrm{Kp}$ can be a suitable parameter to analyze the evolution of the daily irregularities pattern, and it can be used as a proxy for modeling of the ionospheric irregularities oval's position (e.g., Cherniak et al. 2014b).

Analysis of the scatter plots with the HROTI values calculated over the region outside the polar cap demonstrates some decrease in the data scattering and slightly bit higher correlation coefficients comparing with the results that included the polar cap. We suggest that for this severe geomagnetic storm, the major part of the high-latitude ionospheric irregularities occurred within the region of $60-75^{\circ}$ MLAT. This is in accordance with the location of the auroral oval nowcasted by the OVATION Prime model.

\section{Conclusions}

We report first results on the intensity of the highlatitude ionospheric irregularities and its dependence on the auroral activity indices during one of the largest storms of the current solar cycle-the St. Patrick's Day storm of 17 March 2015. The obtained results show that the dynamics of the high-latitude ionospheric irregularities and the ROTI intensity strongly depend on both the auroral electrojet and the auroral hemispheric power indices. The best correlation (0.85) was found with the auroral hemispheric power index, nowcasted by the OVATION model.

Joint analysis of the GPS TEC and the OVATION Prime model of the auroral precipitation demonstrate a very 
good agreement between the hemispheric averages of irregularity intensity and the equatorial border of the ionospheric irregularities on the one hand and the modelderived auroral precipitation level and the aurora oval position on the other hand. Some differences between the occurrence of irregularities in the ROTI maps constructed with the GPS data and the simulated aurora oval shape can be explained by the storm-induced dynamic processes in the ionosphere (e.g., SED, TOI, SAPS, and plasma instabilities), which could not be accounted in the precipitation model. Thus the GPS TEC fluctuation measurements can be used effectively for detection of the high-latitude ionospheric irregularities caused by the direct particle precipitation, as well as the ionospheric irregularities due to dynamic plasma processes in polar ionosphere during the main phase of the geomagnetic storm.

High correlations between of the GPS fluctuation activity and the auroral activity indices suggest a possibility to use the indices as potential drivers for empirical modeling of the ionospheric irregularities occurrence and intensity in the polar and auroral latitudes. OVATION Prime model is directly driven by the solar wind parameters both measured in real time and forecasted. The model is able to provide forecasts for up to $2 \mathrm{~h}$ in advance. The model with solar wind-magnetosphere coupling function predicts auroral power significantly better than $\mathrm{Kp}$ or other traditional parameters (Newell et al. 2014). High correlations between the intensity of the GPS-based ionospheric irregularities and the HP index suggest that quantitative relationship between particle precipitation and the ionospheric plasma behavior can be obtained. The nowcasted and forecasted HP index can be used as an input parameter in near real time to obtain the first estimation of the severity of auroral ionospheric irregularities. Alerts could be provided to GNSS users even prior the GPS data from the groundbased stations is collected and processed.

\section{Competing interests}

The authors declare that they have no competing interests.

\section{Authors' contributions}

IC designed this study, analyzed the data, and wrote the manuscript. IZ developed software for data processing and helped in interpretation of the data. All coauthors contributed to the revision of the draft manuscript and improvement of the discussion. Both authors read and approved the final manuscript.

\footnotetext{
Acknowledgements

We acknowledge use of the raw GPS data provided by IGS (ftp:// cddis.gsfc.nasa.gov/pub/gps/data/), UNAVCO (ftp://data-out.unavco.org/ pub/rinex/obs/), EUREF (ftp://rgpdata.ign.fr/pub/data/), and Natural Resources Canada (webapp.geod.nrcan.gc.ca) networks. The authors thank the NASA/GSFC's Space Physics Data Facility's OMNIWeb service, for providing OMNI data (ftp://spdf.gsfc.nasa.gov/pub/data/omni) and the program code for CGM coordinates calculation. The AE and Kp indices are provided by the World Data Center for Geomagnetism, Kyoto University (wdc.kugi.kyoto-u.ac.jp). The HP data are provided by the Space Weather Prediction Center (SWPC) of NOAA (http://legacy-www.swpc.noaa.gov/ftpdir/lists/hpi/). Forecast and nowcast results of the Ovation Prime model are provided by the US National Centers for Environmental Information (NCEl) of NOAA (http://www.ngdc.noaa.gov/stp/
}

ovation_prime/data/). We thank the ESA for the SWARM data (https:// earth.esa.int/web/guest/missions/esa-operational-eo-missions/swarm). The auroral model code is provided by the Community Coordinated Modeling Center (CCMC) and Holzworth and Meng (ftp://hanna.ccmc.gsfc.nasa.gov/pub/ modelweb/ionospheric/auroral_oval/feldstein_holzworth/. We are grateful to B.W. Reinisch, University of Massachusetts Lowell, for providing the ionogram data of DIDBase. We are also thankful to RJ Redmon (NOAA, USA) for helpful comments on the OVATION Prime model.

\section{Author details}

${ }^{1}$ Space Radio-Diagnostic Research Center, University of Warmia and Mazury, 2 Oczapowskiego, Olsztyn 10-719, Poland. '2Space Weather Laboratory, Kharkiv, Ukraine. ${ }^{3}$ Inistitute De Physique Du Globe De Paris, Paris, France.

Received: 2 May 2015 Accepted: 27 August 2015

Published: 15 September 2015

\section{References}

Aarons J (1997) Global positioning system phase fluctuations at auroral latitudes. J Geophys Res 102(A8):17,219-17,231. doi:10.1029/97JA01118

Aarons J, Lin B (1999) Development of high latitude phase fluctuations during the January 10, April 10-11, and May 15, 1997 magnetic storms. J Atmos Solar-Terrestrial Phys 61:309-327

Akasofu SI (1964) The development of the auroral substorm. Planet Space Sci 12:273

Akasofu SI (1966) The auroral oval, the auroral substorm, and their relations with the internal structure of the magnetosphere. Planet Space Sci 14(5):587-595

Arnoldy RL, Chan KW (1969) Particle substorms observed at the geostationary orbit. J Geophys Res 74:5019-5028. doi:10.1029/ JA074i021 p05019

Cherniak lu, Krankowski A, Zakharenkova I (2014a) Observation of the ionospheric irregularities over the Northern Hemisphere: Methodology and Service. Radio Sci. 49:653-662. doi:10.1002/2014RS005433

Cherniak I, Zakharenkova I, Krankowski A (2014b) Approaches for Modeling Ionosphere Irregularities Based on the TEC Rate Index. Earth, Planets Sp. 66:165. doi:10.1186/s40623-014-0165-z.

Coster AJ, Colerico MJ, Foster JC, Rideout W, Rich F (2007) Longitude sector comparisons of storm enhanced density. Geophys Res Lett 34(18):L18105. doi:10.1029/2007GL030682

Crowley G, Ridley AJ, Deist D, Wing S, Knipp DJ, Emery BA, Foster J, Heelis R, Hairston M, Reinisch BW (2000) Transformation of high-latitude ionospheric F region patches into blobs during the March 21, 1990, storm. J Geophys Res 105(A3):5215-5230. doi:10.1029/1999JA900357

Emery BA, Coumans V, Evans DS, Germany GA, Greer MS, Holeman E, Kadinsky-Cade K, Rich FJ, Xu W (2008) Seasonal, Kp, solar wind, and solar flux variations in long-term single-pass satellite estimates of electron and ion auroral hemispheric power. J Geophys Res 113(A6):A06311. doi:10.1029/2007JA012866

Fejer BG, Kelley MC (1980) Ionospheric irregularities. Reviews of Geophysics and Space Physics 18(2):401-454

Feldstein YI (1963) Some problems concerning the morphology of auroras and magnetic disturbances at high latitudes. Geomagn Aeron 3:183-192

Foster JC (1993) Storm time plasma transport at middle and high latitudes. J Geophys Res 98(A2):1695

Foster JC, Burke WJ (2002) SAPS: a new categorization for sub-auroral electric fields. Eos (Washington, DC) 83(36):393-394

Foster JC, Coster AJ, Ericson PJ, Holt JM, Lind FD, Rideout W, McCready M et al (2005) Multiradar observations of the polar tongue of ionization. J Geophys Res 110:A09S31. doi:10.1029/2004JA010928

Fuller-Rowell TJ, Evans DS (1987) Height-integrated Pedersen and Hall conductivity patterns. J Geophys Res 92(A7):7606-7618

Gondarenko NA, Guzdar PN (2004) Plasma patch structuring by the nonlinear evolution of the gradient drift instability in the high-latitude ionosphere. J Geophys Res 109:A09301. doi:10.1029/2004JA010504

GUVI TIMED JHU/APL website (2015) guvitimed.hhuapl.edu, guvitimed.jhuapl.edu/ guvi-images/guvi_aur.gif. Accessed 4 July 2015.

Holzworth RH, Meng Cl (1975) Mathematical representation of the auroral oval. Geophys Res Lett 2:377-380

Jacobsen KS (2014) The impact of different sampling rates and calculation time intervals on ROTI values. J Sp Weather Sp Clim 4:A33. doi:10.1051/swsc/ 2014031

Jakowski N, Béniquel Y, De Franceschi G, Hernández-Pajares M, Jacobsen KS, Stanislawska I, Tomasik L, Warnant R, Wautelet G (2012) Monitoring, tracking 
and forecasting ionospheric perturbations using GNSS techniques. J Sp Weather Sp Clim 2:A22. doi:10.1051/swsc/2012022

Jiao Y, Morton YT, Taylor S, Pelgrum W (2013) Characterization of high-latitude ionospheric scintillation of GPS signals. Radio Sci 48:698-708. doi:10.1002/ 2013RS005259

Kamide Y, Kusano K (2015) No Major Solar Flares but the Largest Geomagnetic Storm in the Present Solar Cycle. Sp. Weather 13. doi:10.1002/2015SW001213

Kersley L, Russell CD, Rice DL (1995) Phase scintillation and irregularities in the northern polar ionosphere. Radio Sci 30(3):619-629

Keskinen MJ, Ossakow SL (1983) Theories of high-latitude ionospheric irregularities: a review. Rad Sci 18(6):1077-1091. doi:10.1029/RS018i006p01077

Mcllwain CE (1974) Substorm injection boundaries. In: McCormac BM (ed) Magnetospheric physics. Reidel, Hingham, Mass, pp 143-154

Mitchell CN, Alfonsi L, De Francesci G, Lester M, Romano V (2004) GPS TEC and scintillation measurements from the polar ionosphere during the October 2003 storm. Geophys Res Lett 32:L12S03. doi:10.1029/2004GL021644

Newell PT, Meng Cl, Sibeck DG, Lepping RP (1989) Some low-altitude cusp dependencies interplanetary magnetic field. J Geophys Res 94:8921-8927

Newell PT, Greenwald RA, Ruohoniemi JM (2001) The role of the ionosphere in aurora and space weather. Rev Geophys 39(2):137-149. doi:10.1029/ 1999RG000077

Newell PT, Sotirelis T, Wing S (2009) Diffuse, monoenergetic, and broadband aurora: the global precipitation budget. J Geophys Res 114(A9):A09207. doi:10.1029/2009JA014326

Newell PT, Liou K, Zhang Y, Sotirelis T, Paxton LJ, Mitchell EJ (2014) OVATION Prime-2013: extension of auroral model to higher disturbance levels. Sp Weather 12:368-379. doi:10.1002/2014SW001056

Nishitani N, Hori T, Kataoka R, Ebihara Y, Shiokawa K (2015) Characteristics of ionospheric convection associated with low-latitude aurora observed at Rikubetsu, Hokkaido during the 2015 March storm, paper presented at SuperDARN workshop 2015. Leicester, UK

Noja M, Stolle C, Park J, Lühr H (2013) Long-term analysis of ionospheric polar patches based on CHAMP TEC Data. Radio Sci 48(3):289-301. doi:10.1002/ rds.20033

Phelps ADR, Sagalyn RC (1976) Plasma density irregularities in the high-latitude top side ionosphere. J Geophys Res 81(4):515-523. doi:10.1029/ JA081i004p00515

Pi X, Mannucci AJ, Lindqwister UJ, Ho CM (1997) Monitoring of global ionospheric irregularities using the worldwide GPS network. Geophys Res Lett 24:2283

Prikryl P, Ghoddousi-Fard R, Kunduri BSR, Thomas EG, Coster AJ, Jayachandran PT, Spanswick E, Danskin DW (2013) GPS phase scintillation and proxy index at high latitudes during a moderate geomagnetic storm. Ann Geophys 31:805-816. doi:10.5194/angeo-31-805-2013

Prikryl P, Jayachandran PT, Mushini SC, Richardson IG (2014) High-latitude GPS phase scintillation and cycle slips during high-speed solar wind streams and interplanetary coronal mass ejections: a superposed epoch analysis. Earth Planets Sp 66:62. doi:10.1186/1880-5981-66-62

Reinisch BW, Galkin IA (2011) Global ionospheric radio observatory (GIRO). Earth Planets Sp 63(4):377-381

Russell C (2000) The polar cusp. Adv Sp Res 25(7-8):1413-1424. doi:10.1016 S0273-1177(99)00653-5

Skone S, Cannon ME (1995) Ionospheric effects on differential GPS applications during auroral substorm activity. ISPRS J Photogram Remote Sens 54:279-288

Smith AM, Mitchell CN, Watson RJ, Meggs RW, Kintner PM, Kauristie K, Honary F (2008) GPS scintillation in the high arctic associated with an auroral arc. Space Weather 6:S03D01. doi:10.1029/2007SW000349

Streltsov AV, Pedersen TR, Mishin EV, Snyder AL (2010) lonospheric feedback instability and substorm development. J Geophys Res 115(A7):A07205. doi:10.1029/2009JA014961

Tsunoda RT (1988) High-latitude F region irregularities: a review and synthesis. Rev Geophys 26(4):719-760

Valladares CE, Villalobos J, Sheehan R, Hagan MP (2004) Latitudinal extension of low-latitude scintillations measured with a network of GPS receivers. Ann Geophys 22(9):3155-3175. doi:10.5194/angeo-22-3155-2004

van der Meeren C, Oksavik K, Lorentzen D, Moen Jl, Romano V (2014) GPS scintillation and irregularities at the front of an ionization tongue in the nightside polar ionosphere. J Geophys Res Sp Phys 119:8624-8636. doi:10.1002/2014JA020114

Wanner B. (2015), DR \#127: Effect on WAAS from lono Activity on March 17-18, 2015, WAAS Technical Report at the WAAS Test Team web-page, 2015.
Accessed 14 July 2015. http://www.nstb.tc.faa.gov/Discrepancy\%20Reports \%20PDF/DR\%20127\%20Effect\%20on\%20WAAS\%20from\%20lono\%20 Activity\%20March\%2017\%202015.pdf

Watson C, Jayachandran PT, Spanswick E, Donovan EF, Danskin DW (2011) GPS TEC technique for observation of the evolution of substorm particle precipitation. J Geophys Res 116:A00190. doi:10.1029/2010JA015732

Weber EJ, Klobuchar JA, Buchau J, Carlson HC, Livingston RC, de La Beaujardiere O, McCready M, Moore JG, Bishop GJ (1986) Polar cap F layer patches: structure and dynamics. J Geophys Res 91(A11):12,121-12,129. doi:10.1029/ JA091iA11p12121

Zou S, Ridley AJ, Moldwin MB, Nicolls MJ, Coster AJ, Thomas EG, Ruohoniemi JM (2013) Multi-instrument observations of SED during 24-25 October 2011 storm: implications for SED formation processes. J Geophys Res Sp Phys 118(12):7798-7809. doi:10.1002/2013JA018860

\section{Submit your manuscript to a SpringerOpen ${ }^{\odot}$ journal and benefit from:}

- Convenient online submission

- Rigorous peer review

- Immediate publication on acceptance

- Open access: articles freely available online

- High visibility within the field

- Retaining the copyright to your article

Submit your next manuscript at $\gg$ springeropen.com 